\title{
Comparative Analysis of Energy in “Hua'er” Folk Song Acoustics
}

\author{
Yanbing Ding ${ }^{\mathrm{a}}$, Yonghong $\mathrm{Li}^{\mathrm{b}}$, * \\ Key Lab of China's National Linguistic Information Technology, Northwest Minzu University, Lanzhou, \\ 730030 China \\ a570566007@qq.com, blyhweiwei@126.com \\ *corresponding author
}

Keywords: "Hua'er", Energy, Acoustic Analysis.

\begin{abstract}
Hua'er" folk song is the first project in Gansu that has won title of "World Intangible Cultural Heritage", and is an important part of folk songs of Northwest China. This paper, through comparative analysis of the energy differences between a number of "Hua'er" songs' male and female voices' singing, explores the acoustic characteristics thereof, and draws such conclusions: when speakers are singing "Hua'er", the energy of male and female voices tends towards concentrated distribution on the whole, and taking on normal distribution; when male voices are singing, the energy span is greater than female voices and the energy distribution is more concentrated, while female voices' energy is dispersed and clearly cadenced.
\end{abstract}

\section{Introduction}

Hua'er is a kind of folk song unique to Northwest China, most widely circulated especially in Gansu, Qinghai and Ningxia, and is a treasure of folk literature and art in the Great Northwest ${ }^{[1]}$. Its singing style consists of basic singing style and special singing style, of which the basic singing style includes natural voice, treble, and real tone and falsetto. Natural voice, is to sing with one's true voice, which can sing a touching, appealing artistic effect; "treble" is also known as "falsetto", which can well express a song's content ${ }^{[2]}$. In order to make the tone more euphemistic and the intonation more obvious in the singing process, Hua'er also has a large amount of voice-retouching skills, and such is its special singing style, which includes appoggiatura, trill, swing voice, prolongation of tune, etc. Hua'er songs sung with real tone, falsetto, and voice-retouching skills are loud and clear, sonorous, and melodious, and have a refreshing taste of the wildness and an atmosphere of the plateau. By means of experimental phonetics, this paper uses phonetic experiment instruments and the knowledge of linguistics and applied linguistics to make an acoustic analysis of the energy data of Hua'er singers' male voices and female voices, and thereby obtain their energy acoustic characteristics. Then, based on quantitative analysis of male and female voices' energy difference, we set up a Hua'er energy database, which provides a more favorable reference for digital inheritance and protection of Hua'er.

\section{Experimental Method}

This paper has collects more than ten representative, typical songs from Northwest China, and invites 2 male and 2 female speakers (singers). The hardware for recording includes external sound card, clipper microphone, sound console, laptop, etc.; the software includes Audition1.5, which is used to record voice signal, Praat, which is used to extract energy parameters, and SPSS20.0, which is used to make a statistic analysis of the data. 


\section{3. “Hua'er” Energy Analysis}

Energy reflect the loudness of a sound (voice) ${ }^{[3]}$. By means of experimental phonetics, this paper, from the perspective of energy distribution, analyzes the phonetic difference between male and female singers in Hua'er basic singing style and special singing style, and discusses the acoustic characteristics of energy in the singing process of "Hua'er". This section extracts the overall energy of "Hua'er" folk songs Pony Tune (m1), Three Tunes of Hezhou (m2), Pink Flower Tune (f1), Brother is a White Cotton in the Sky (f2) and La La Tune (m1, f1), and uses vertical and horizontal comparative analysis methods to comprehensively analyze Hua'er singing, and explore the energy distribution difference between male and female voices' in the singing process of "Hua'er" and the overall energy distribution regularities.

\subsection{Overall energy analysis of male and female voices when singing different songs}

The 2 male voices and 2 female voices are selected to respectively sing different "Hua'er" songs, and the extracted overall energy data are shown in the table below:

Table 1 Overall energy data of male and female voices singing different songs

\begin{tabular}{ccccc}
\hline $\begin{array}{c}\text { Speaker- } \\
\text { Song }\end{array}$ & $\begin{array}{c}\text { m1-Pony } \\
\text { Tune }\end{array}$ & $\begin{array}{c}\text { m2-Three Tunes of } \\
\text { Hezhou }\end{array}$ & $\begin{array}{c}\text { f1-Pink Flower } \\
\text { Tune }\end{array}$ & $\begin{array}{c}\text { f2-Brother is a White Cotton } \\
\text { in the Sky }\end{array}$ \\
\hline $\begin{array}{c}\text { Duration (s) } \\
\text { Energy }\end{array}$ & 80.95 & 55.15 & 85.63 & 68.63 \\
$\begin{array}{c}\text { Min(dB) } \\
\text { Energy }\end{array}$ & 12.96 & 19.26 & 19.75 & 14.45 \\
$\begin{array}{c}\text { Max(dB) } \\
\text { Energy }\end{array}$ & 85.54 & 86.06 & 82.81 & 78.17 \\
Mean(dB) & 65.93 & 67.09 & 63.27 & 58.29 \\
\hline
\end{tabular}

It can be found from the above table:

The energy comparison between the four songs show, when male and female voices are singing different "Hua'er" songs, energy change is different. First, when male and female voices are singing Hua'er, the average energy is $58-68 \mathrm{~dB}$; second, the greatest energy value of male voices $\mathrm{m} 1, \mathrm{~m} 2$ is obviously higher than that of female voices $\mathrm{f} 1$, f2, the highest energy of male voices is $3.25 \mathrm{~dB}$ greater than that of female voices, and the lowest energy of male voices is $1.49 \mathrm{~dB}$ lower than that of female voices; third, the difference between the whole-song energy maximum value and minimum value of speakers $\mathrm{m} 1$ and $\mathrm{m} 2$ is $72.58 \mathrm{~dB}$, and $66.80 \mathrm{~dB}$ respectively, and the difference between the whole-song energy maximum value and minimum value of speakers $\mathrm{f} 1$ and $\mathrm{f} 2$ is $63.06 \mathrm{~dB}$ and $63.72 \mathrm{~dB}$ respectively, that is, the difference between energy maximum value and minimum value of male voices is higher than that of female voices .

This indicates that when male voices are singing, their sound intensity span is larger than female voices, male voices' sound is brighter and more penetrating, and always maintain a loud and sonorous sound when singing; their expanded range enables them to not only sing a high pitch, but also show mellow, full-bodied tenor and bass, highly expressive. Female voices are and clearly cadenced, sound free and pure, and their expression of emotions is more delicate. Compared with general folk singing style and bel canto, Hua'er's overall energy is not very high, but is very concentrated, and each song's energy takes on a trend of stair-like rise. Besides, when male speakers are singing Hua'er, the energy is concentrated, and when female speakers are singing Hua'er, the energy is dispersed.

\subsection{Overall energy analysis of male and female voices when singing the same song}

M1 and f1 are selected to sing La La Tune, and the overall energy data of male and female voices singing the same song are extracted, as shown in the table below: 
Table 2 overall energy data of male and female voices singing the same song

\begin{tabular}{cccccc}
\hline Speaker & Song & Duration (s) & $\begin{array}{c}\text { Energy } \\
\text { Min (dB) }\end{array}$ & $\begin{array}{c}\text { Energy } \\
\text { Max (dB) }\end{array}$ & $\begin{array}{c}\text { Energy } \\
\text { Mean (dB) }\end{array}$ \\
\hline m1 & La La Tune & 89.67 & 17.62 & 89.21 & 63.65 \\
$\mathrm{f} 1$ & La La Tune & 65.22 & 19.12 & 79.16 & 63.50 \\
\hline
\end{tabular}

It can be found from the above table:

First, when male and female voices are singing the same Hua'er La La Tune, their singing \& handling methods are different, as the singing duration of male voices is $24.45 \mathrm{~s}$ longer than that of female voices, and this indicates that, while singing, different Hua'er singers vary in their pause of each line of lyrics and in the length of each sound they pronounce, Hua'er singers would perform a Hua'er tune according to their own understanding and feeling. The overall highest energy of male voices is $13.05 \mathrm{~dB}$ higher than the highest energy of female voices, overall lowest energy is $1.50 \mathrm{~dB}$ lower than that of female voices, and the overall average energy of male voices is $0.15 \mathrm{~dB}$ higher than female voices. Second, in terms of the overall singing of this Hua'er tune, the highest energy reflects such a characteristics: male voices' highest energy is higher than female voices' highest energy, and lowest energy is lower than female voices', which indicates that the difference between highest energy and lowest energy of male voices singing is greater than that of female voices, that is, the sound intensity span of male voices singing is larger than that of female voices. When different people sing the same Hua'er tune, the taste would be different, and this tallies with the common saying that "Of ten people singing a Hua'er, nine will have a different flavor." In order to more fully illustrate the energy difference between a man and a woman singing the same La La Tune, SPSS20.0 is used to make the following histograms.

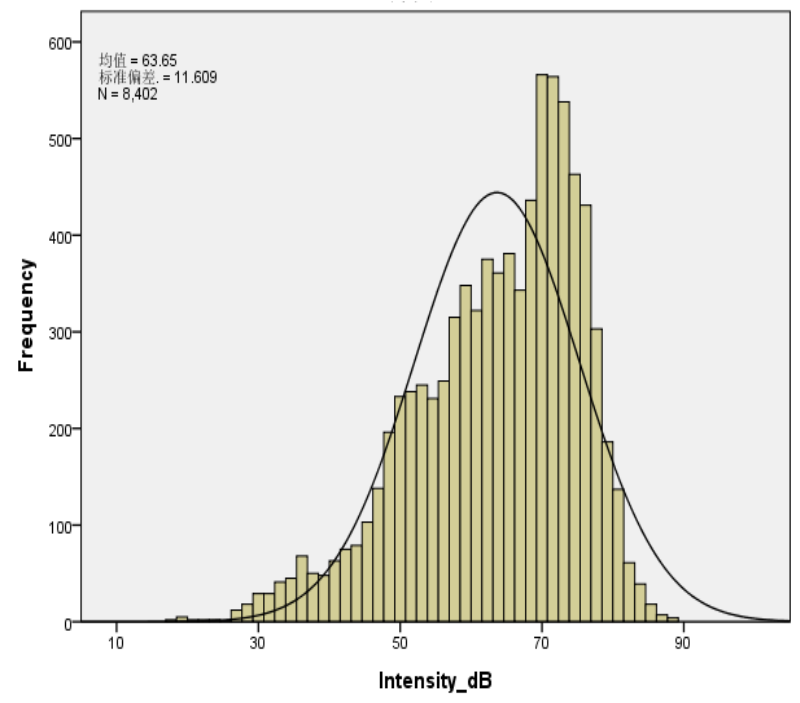

Fig. 1 M1 overall energy distribution diagram

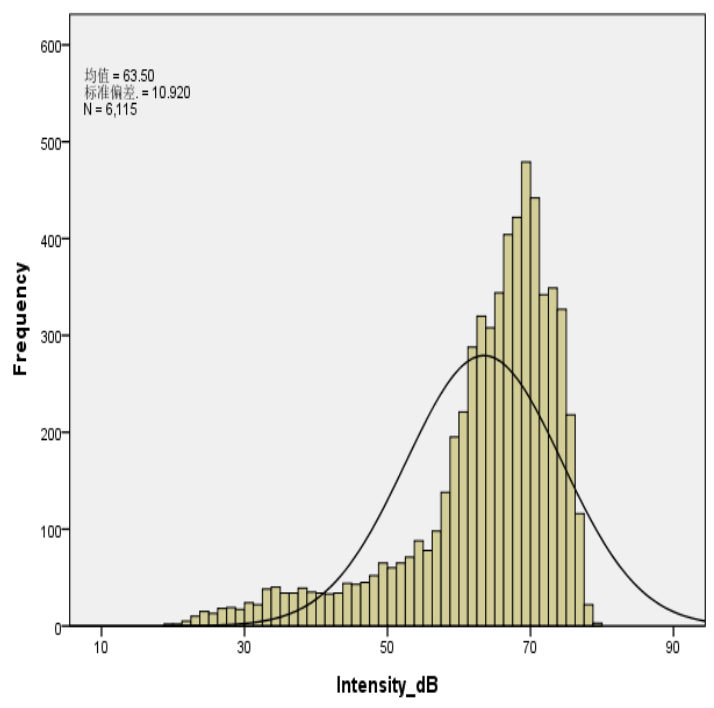

Fig. 2 F1 overall energy distribution diagram

It can be seen from the above diagrams: First, Hua'er energy distribution of both male and female voices singing takes on normal distribution; Second, m1's overall energy concentrated distribution area is $70-73.75 \mathrm{~dB}$, accounting for $13.81 \%$ of the total data, f1's overall energy concentrated distribution area is $66.25-71.25 \mathrm{~dB}$, accounting for $7.85 \%$ of the total data; male and female voices' every concentrated values have no significant difference, but concentrated distribution proportion of male voices is two times the female voices, which indicates that male voices' energy is more concentrated, and male voices' energy standard difference is greater than female voices; the smaller the standard difference, the smaller the array dispersion is, that is, male voices' energy is relatively more concentrated than female voices.

This illustrates that, when singing, Hua'er singers' energy distribution is balanced, and their intensity and tone color do not change much, which makes the overall energy value show a high degree of fit; meanwhile, the singers need to guide their breath to form a strong supporting point, so that they can control their breath evenly, more freely and easily control the change in singing power, 
thereby making Hua'er emotional expression more real, natural and affectionate. Whereas, male voices' La La Tune sounds cheery and drawn-out, while female voices' cheerful and light-hearted, in a way that is closer to rapping.

\section{Conclusion}

This paper tries using research method of experimental phonetics to approach "Hua'er". Through comparative analysis of the energy of folk song male and female voices' singing "Hua'er", this paper summarizes the acoustic characteristics thereof, providing convenience for better inherit "Hua'er" folk songs, and providing some beneficial thoughts for the scientific implementation of the protection of non-material cultural heritage.

\section{Acknowledgements}

The work supported by Project of Central Universities of Northwest Minzu University: Multimode Phonetic Research (31920160002).

\section{References}

[1] Qi Xiaoping. A Study of Taomin Hua'er. Nationalities Publishing House, 2013.11-19.

[2] Chen Yuanlong. A New study on China Hua'er. Gansu Cultural Publishing House. 2004.99-109.

[3] Kong Jiangping. A Basic Course in Experimental Phonetics [M]. Peking University Press. 2015.7-15. 